geophysics, particle physics and space science, primarily in the United States.

They developed a quantitative approach using statistical and organizational concepts. They shy away from extended case studies, as it can be difficult to generalize from them, but their studies retain some individual character, to give far more than a dry bibliometric analysis of who did what with whom. This approach helps them provide an enlightening, easy to read and sometimes surprising view of how collaborations work.

Trust, conflict and performance are crucial factors. One counter-intuitive finding is that trust does not correlate with performance. It is widely assumed that trust is required to achieve success, but this may stem from the fact that lower levels of trust tend to result in higher levels of conflict. Conflict is unpleasant for individual scientists but is not necessarily a barrier to progress. In fact, many collaborations inherently tend to protect against damage from conflict between members.

There are several types of organizational structure, characterized mostly by the breadth of activities and manner of governance. Most types occur in a range of scientific fields. One sort - the 'quasi-Athenian democracy', typified by bottom-up consensus building - is almost unique to particle physics. The book's authors argue that this model would not benefit other science communities, and indeed, as particle-physics collaborations grow larger, they might need to change from this traditional form.

One weakness of this characterization of particle physics is that collaborations have already grown in size well beyond the cases studied, all of which occurred in the 1970s and 1980s. It would be interesting to compare two competing but nearly identical projects, such as the BaBar experiment at the Stanford Linear Accelerator Center in California and the Belle experiment at the High Energy Accelerator Research Organization (KEK) in Tsukuba, Japan. These have different organizational and management styles, with different strengths

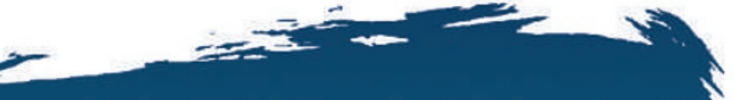

Hadron Collider at CERN, the European particle-physics laboratory near Geneva. Do those projects fit the authors' models even though international diplomatic and political factors have played a more prominent role?

Under what conditions is collaboration desirable? This, too, needs further exploration, especially as more projects are located and managed in large laboratories. A recent report on university participation in US particle physics by the Department of Energy's High Energy Physics Advisory Panel suggests that the concentration of collaborative projects in large laboratories could be weakening the and weaknesses.

The study's applicability is limited by the US-centric and physics-dominated data set. It would have been interesting to read about international collaborations, such as the ITER fusion-reactor project in Cadarache, France, the Human Genome Project and the Large physics effort in universities and contributing to structural deficiencies in the science programme.

David Harris is editor-in-chief of Symmetry magazine at the Stanford Linear Accelerator Center, 2575 Sand Hill Road, Menlo Park, California 94025, USA.

\title{
Eras of judgement
}

\section{Objectivity \\ by Lorraine Daston \& Peter Galison \\ Zone Books, MIT Press: 2007.500 pp. \\ $€ 25.95, \$ 38.95$}

\section{Theodore M. Porter}

All scientists think they know what objectivity is. But objectivity has a history full of fascinating changes of sense, and now bears several different meanings. Most involve an absence: of distortion; of human bias or subjectivity; or of the particularities of location and culture. It is one of the more austere virtues, often seen as a stern judge that disallows ornamentation.

In their book Objectivity, Lorraine Daston and Peter Galison pursue the idea that we can best explore the many meanings of objectivity through an examination of images - their book is essentially about the ideal of objectivity as applied to scientific atlases, or reference books of illustrations. In such works, objectivity is largely about restrictions on the composition and presentation of scientific images. Objectivity, however, offers a cornucopia of images ranging from plants and birds to embryos and snowflakes, and it is enriched by the authors' expert sleuthing and wide intellectual reach.

The heart of objectivity, for Daston and Galison, is 'mechanical objectivity', which had its heyday from about 1850 to 1920 . The phrase implies that scientists proceeded methodically, using automation whenever possible, to reduce human intervention to a minimum. This era of impersonal objectivity was preceded, the authors propose, by one of 'truth to nature' and succeeded by one of 'trained judgement'.

Using such names for historical periods may seem incendiary, first by implying that objectivity has had its day, and further by placing it in opposition to both truth and expert judgement. But the authors have very particular meanings in mind. The terminology is confusing, though, because scientists rarely used the word 'objectivity' until some decades into the

\section{Capitalism as if the World Matters}

by Jonathon Porritt (Stylus/Earthscan,

\section{$\$ 24.95 / E 16.99)$}

This updated edition of Jonathon Porritt's influential book calling for renewed vigour in the environment movement has an extended section on the politics of climate change, including details of the massive upsurge in religious engagement with the topic in the United States. The core message is the same - that capitalism doesn't have to cost the Earth.

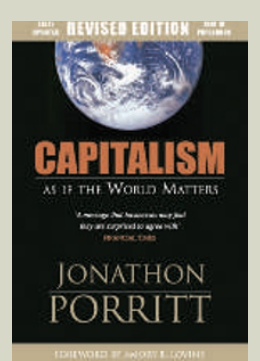

Sleepfaring: A Journey Through the Science of Sleep

by Jim Horne (Oxford Univ. Press, $\$ 12.95, \notin 7.99$ ) We all do it, but many of us don't get enough of it. So how much sleep do we need, and what good does it do? Jim Horne's travel guide through the land of nod brings in insights from up-to-date physiology, psychology, medicine and neuroscience. Horne runs the Loughborough Sleep Research Centre in the United Kingdom. slo.epfaring 
era that Daston and Galison name for it.

Objectivity here is more about morality than validity. Mechanical objectivity made suppression of self a duty, a triumph of abstemious will over the prideful claim of competence to judge and interpret. The contrast between mechanical objectivity and devotion to truth is subtle but important. A uniformly sharp photograph might well be confusing, masking the main point in irrelevant detail. It is easier to identify a flower or recognize a diseased kidney from an idealized drawing than from an unretouched photograph.

Daston and Galison define the era of mechanical objectivity by a profound reluctance of scientists seeking to illustrate their work to stray from the rigorous accuracy of the camera. Yet photographic accuracy, at least until 1890, was far from rigorous. Choices had to be made in preparing materials, composing, illuminating and framing the picture, and sometimes retouching an image, and the technology of photographic reproduction in the 1880s involved intense human labour. The language of objectivity, then, did not so much distinguish photography from drawing as mark off certain ways of preparing photographs from others. An 'objective' image was one that minimized the effects of human intervention.

In contrast, naturalists of Daston and Galison's earlier 'truth-to-nature' era felt no such compunctions. They used illustrations to get at something more fundamental than the individual: an underlying type. This is 'truth' in a very special sense. The eighteenthcentury naturalists Carl Linnaeus and René Réaumur supervised their artists meticulously, not to ensure that they drew a specimen accurately, but to make sure that they departed from its particularity where this could reveal a deeper level of truth.

The authors argue that science and art diverged around 1850, with science insisting on objectivity in its ascetic form, and art rejecting the mere reproduction of what can be seen in the world. They propose that different forms of objectivity arose in conjunction with new understandings of the 'scientific self', which by 1850 had become quite different from the artist. This focus on the changing character of the scientist offers important insights, but the authors overstate their case for the rupture between science and art. The very phrase 'truth to nature' is associated specifically with the preRaphaelites, a mid-nineteenth-century artistic movement grounded in an admiration for the writer and aesthete John Ruskin (indeed Tate Britain had a major exhibition in 2004 called "Pre-Raphaelite Vision: Truth to Nature"). Ruskin, whom Daston and Galison fail to mention, was as committed to the union of scientific and artistic perspectives as the poetnaturalist Johann Wolfgang von Goethe, who features prominently.

How could objectivity interfere with truth? Daston and Galison introduce this notion at the outset with the story of the British physicist Arthur Worthington. In 1875, Worthington began chronicling the beautiful symmetries of fluid motion revealed by a droplet of mercury hitting a clear glass plate. In 1894 he finally captured the splash in a photograph. To his dismay, it was a mess, with none of the perfection he thought he had witnessed. Did the mechanical image occasion a sacrifice of truth? Yes, if 'truth' refers to such elegant forms as admired by Goethe a century earlier. In a more prosaic sense, Worthington had finally got it right. He concluded, sadly, that the symmetries he thought he saw were artefacts of his own flawed vision.

The authors draw back from claiming in a strict sense that objectivity was invented, had its day in the sun, and then passed away. Yet something like this, much qualified, is the organizing principle of the book. This is problematic, not least because the argument is based on the special case of scientific atlases and then extended to all of science. Can Daston and Galison really claim that trained judgement never existed as a conscious alternative to unthinking routines of objectivity until about 1920? They are, however, persuasive in arguing that a vast expansion of scientific educa-

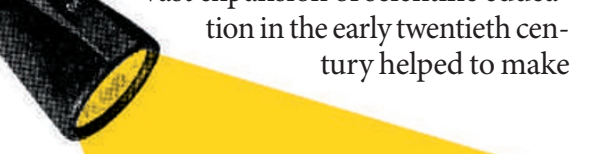
tury helped to make

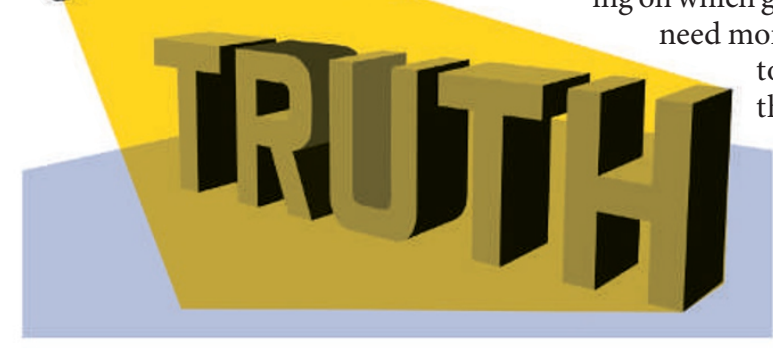

expert judgement more acceptable to science.

By this time, scientists and other professionals were arguing with increasing conviction that mechanical procedures could not really get at what is most interesting. The interpretation of images, they said, depended on a capacity to see 'family resemblance', which scientists, with the aid of well-drawn images, could learn to recognize reliably. Daston and Galison demonstrate, with wonderful insight, that this notion of family resemblance was simultaneously scientific, philosophical and pictorial. Ludwig Wittgenstein, in enunciating it, referred back to some striking composite photographs through which the statistician and eugenicist Francis Galton tried to establish racial and social types. Scientists of this period repeatedly likened the analysis of an image in physics or medicine to detecting racial background from a photograph.

The book concludes with an analysis of images from today, perhaps a fourth epoch in the history of objectivity. Modern techniques of image production at the nanoscale use processes that record themselves (Daston and Galison call these 'presentations' rather than 'representations'). These attest to the extraordinary merging, in certain areas, of technology with science, and sometimes also with marketing. The commercialization of science presents its own problems, for scientific objectivity is about more than communication among scientists. As important today are the views of political leaders and the public. Modern scientists, enmeshed in elaborate systems of recruitment, training and communication, may have less need of mechanical objectivity than their nineteenth-century counterparts, but they find it difficult to speak to the public with the same kind of assurance. Critics of the science establishment have turned the rhetoric of (mindless) mechanical objectivity against science, objecting to the sensible but unrigorous application of experience and understanding on which good science depends. Scientists more than ever before to gain, and to deserve, public respect for their skilled work and uncorrupted expert judgement. Theodore M. Porter is in the Department of History, University of California, Los Angeles, Los Angeles, California 90095-1473, USA.

\section{Things That Talk: Object Lessons from Art} and Science

edited by Lorraine Daston (Zone Books, \$21.95)

This collection of nine essays, edited by science historian Lorraine Daston, explores how objects attract meanings and cultural significance - and shows how they then become crystallization points for discussion. Each essay singles out one thing for close attention, including a Bosch drawing, soap bubbles, Rorschach blots and paintings by Jackson Pollock.

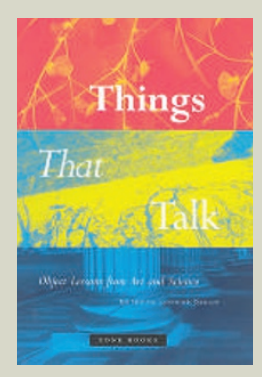

The Best American Science Writing 2007 edited by Gina Kolata (Harper Perennial, \$14.95) The fifth anthology of features and essays about science is compiled by The New York Times' science writer, Gina Kolata. The New Yorker wins six of the 20 slots, including one for its unforgettable article 'Manifold destiny' about Grigory Perelman and the Poincaré conjecture. Also prominent is writing about the brain, notably by Joshua Davis of Wired on the condition of face blindness.

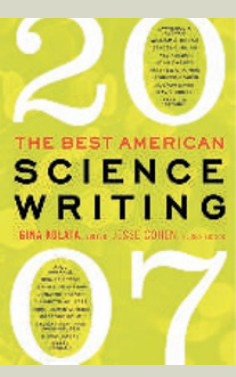

